\begin{abstract}
Medicinski fakultet Banja Luka, Republika Srpska, Zavod za anatomiju’
Originalni naučni rad

Medicinski fakultet Beograd, Institut za anatomiju

Zavod za rehabilitaciju "Dr Miroslav Zotović", Banja Luka”

Original study

Fakultet veterinarske medicine, Beograd ${ }^{4}$

UDK $611.81: 612.823 .08$

DOI:10.2298/MPNS1002051S

\section{DIGITALNA MORFOMETRIJSKA STUDIJA EKSTRASULKUSNE POVRŠINE GIRUSA CINGULI ČOVEKA}

\title{
DIGITAL MORPHOMETRIC STUDY OF THE EXTRASULCAL SURFACE OF THE CINGULATE GYRUS IN MAN
}

\section{Goran SPASOJEVIĆ ${ }^{1}$, Slobodan MALOBABIĆ ${ }^{2}$, Zlatan STOJANOVIĆ ${ }^{\text {, Slavica JANDRIĆ }}$ i $^{3}$ Milena ĐORĐEVIĆ 4}

\begin{abstract}
Sažetak - Analiza morfoloških tipova i ekstrasulkusne (vidljive) površine girusa cinguli obuhvatila je 42 mozga ( 84 hemisfere) odraslih (26 muškaraca i 16 žena, 20-65 godina). Po fiksiranju 10\% formalinom i disekciji vršena je morfološka tipizacija. Standardizovana digitalna AutoCAD planimetrija ekstrasulkusne površine girusa cinguli vršena je u koordinatnom sistemu interkomisuralne linije. Opisali smo tri morfološka tipa girusa cinguli:kontinuirani $(34.5 \%)$. segmentirani $(35,7 \%)$ i dvostruki paralelni tip $(29.8 \%)$. Nema statistički značajnih razlika u učestalosti ovih tipova girusa cinguli prema strani (desna/leva) ili polu osoba ( $>0.05$ ). Ekstrasulkusna površina girusa cinguli na levim $\left(14,58 \mathrm{~cm}^{2}\right)$ statistički je značajno veća $(p<0,05)$ nego na desnim hemisferama $\left(13,45 \mathrm{~cm}^{2}\right)$. Takođe je signifikantno veća $(\mathrm{p}<0,05)$ ekstrasulkusna površina levog girusa cinguli muškaraca $\left(15,9 \mathrm{~cm}^{2}\right)$ nego žena $\left(13,6 \mathrm{~cm}^{2}\right)$. dok za desnu vijugu razlika nije bila signifikantna. Iako sama morfološka analiza to nije pokazala. digitalna planimetrija ekstrasulkusne površine girusa cinguli pokazala je polne i desno-leve morfometrijske razlike.

Ključne reči: Girus cinguli + anatomija i histologija: Čovek: Polne karakteristike; Morfogeneza: Telesna tipizacija
\end{abstract}

\section{Uvod}

Gyrus cinguli (GC) ili pojasna vijuga velika je vijuga limbičkog pojasa medijalne strane hemisfera, razdvojena od korpusa kalozuma pomoću sulkusa korporis kalosi (sulcus corporis callosi), dok ga dorzalno sulcus cinguli i sulcus subparietalis odvajaju od perifernog (lobarnog) pojasa. Prednji kraj GC se ispod genu corporis callosi nastavlja u areu supkalozu (area subcallosa), a završni deo ispod splenijuma (splenium corposi callosi) u isthmus gyri cinguli.

Pojasna vijuga je sastavni deo limbičkog sistema koji je neposredno odgovoran za motivaciju, emotivno ponašanje (autonomne i seksualne funkcije), procese pamćenja i predstavlja region povezivanja (interface) pažnje i emocija [1-4]. Vidljiva, ekstrasulkusna površina kore GC obuhvata aree $23,24 \mathrm{i}$ 29 [5]. Area 24 zauzima prednji deo GC, napred i dorzalno je cingulofrontalna prelazna kora (area 32), u srednjem delu GC je area 23, dok je area 29 u zadnjem delu GC, kao i prelazna cinguloparijetalna area $31[5,6]$. Podraživanje aree 24 dovodi do niza autonomnih reakcija: usporavanja rada srca i disanja, pada krvnog pritiska, piloerekcije, midrijaze, snižavanje tonusa mišića [2]. Prednji cingularni korteks je i visokospecifična motorna zona, a zadnji mesto multimodalne senzorne konvergencije $[7,8]$.

Zbog ovakve uloge GC, promene njegovih morfometrijskih parametara mogu pratiti različite psihičke poremećaje. Posebno su izražene volu-

Ovaj rad je delom finansiran iz projekta br. 156031 Ministarstva za nauku i tehnologiju Republike Srbije. metrijske promene prednjeg cingularnog korteksa kod shizofrenije $[9,10]$, kod koje, pored redukcije raznih parametara (debljina kore i njenih slojeva, veličina i gustina neurona), dolazi i do hipoperfuzije pomenutog područja [11]. Kod ove bolesti dolazi i do smanjenja gustine sive mase u zadnjem cingularnom korteksu [9], koji se inače dovodi u vezu i sa procesiranjem boli [12].

Izgled i veličina GC čoveka uslovljeni su morfologijom sulkusa cinguli (sulcus cinguli) i okolnih žlebova. Ako je sulcus cinguli jedinstven, tada je GC tipičnog (konkavnog) izgleda, ali ako je sulcus cinguli segmentiran u više delova, tada mnogobrojne prelazne vijuge vežu GC sa vijugama lobarnog pojasa medijalne strane hemisfera $[13,14]$. U slučaju postojanja sulkusa paracinguli (sulcus paracinguli), postoji i dvostruka pojasna vijuga (double parallel type) u prednjem delu [15].

Cilj našeg rada je da se preko analize učestalosti pojedinih tipova i merenjem ekstrasulkusne (vidljive) površine GC, doprinese izučavanju desno-leve asimetrije i polnog dimorfizma čovekovog mozga, a time i boljoj dijagnostici složenih poremećaja moždanih funkcija.

\section{Materijal i metode}

Istraživanje je vršeno na 42 mozga ( 84 hemisfere) bez patoloških promena koji potiču od odraslih osoba oba pola (26 muškaraca i 16 žena, starosti 20 -65 godina). Po fiksaciji u $10 \%$ rastvoru formalina tokom 3-4 nedelje napravljeni su mediosagitalni preseci, a zatim su skidane moždane ovojnice. Medijalnu stranu mozga fotografisali smo digitalnim 


\section{Skraćenice}

GC - gyrus cinguli (pojasna vijuga)

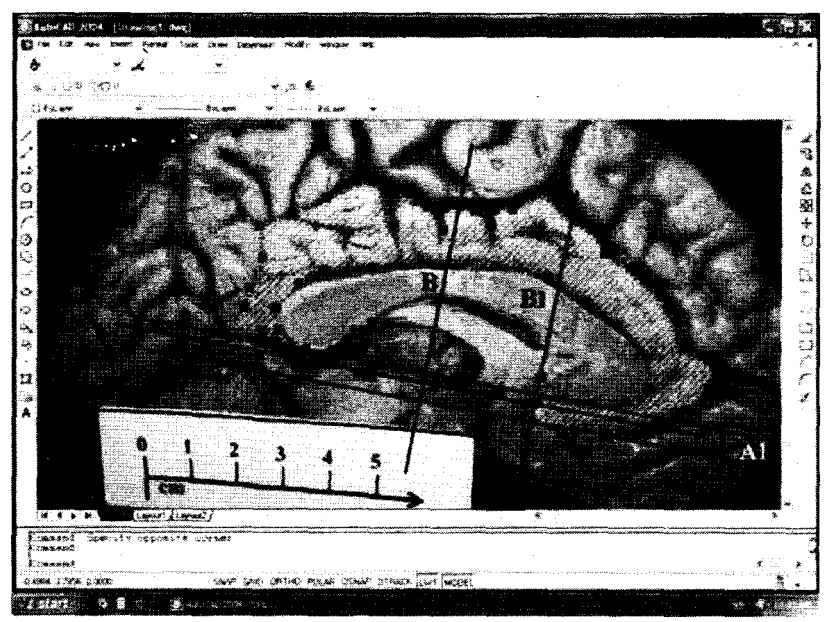

Slika 1. AutoCAD morfometrija ekstrasulkusne (vidljive) površine girusa cinguli i određivanje njegovih granica.

A - interkomisuralna osa (commissura anterior - commissura posterior); $\mathrm{B}$ - prava na interkomisuralnu osovinu $(\mathrm{B}+\mathrm{A}) . \mathrm{Za}$ određivanje granica girusa cinguli korišćene su tačka a - na tangenti paralele liniji A na splenium corporis callosi i tačka al na tangenti linije Al (paralela liniji A) na rostralni produžetak sulkusa cinguli, kao i B1 (paralela liniji B), kroz rostrum corporis callosi.

Fig. 1. The AutoCAD morphometry of the extrasulcal (visible) surface of the cingulate gyrus and determination of its boundaries.

$A$ - intercommissural line (commissura anterior - commissura posterior); $B$ - axis vertical to the intercommissural line $(B-A)$. To determine the boundaries of the cingulate gyrus following marks were used: a point - on the tangent line parallel to the line $A$ on the splenium corporis callosi and al point - on the tangent line AI (parallel to line A) on the rostral end of the cingulate sulcus and line BI (parallel to B) through the rostrum corporis callosi

aparatom visoke rezolucije ( $8 \mathrm{MB}$ ) na standardnom rastojanju od $50 \mathrm{~cm}$ i pod pravim uglom na ravan površine medijalne strane hemisfera mozga. Svaka digitalna fotografija je kalibrisana i označena koordinatnim osama A i B, koje su korišćene za dalju standardizaciju granica prednjeg i zadnjeg dela GC. Pri tome, A (transkomisuralna) osa prolazi kroz najispupčenije tačke komisure anterior i komisure posterior u III moždanu komoru, a B-osa je uspravna pod uglom od $90^{\circ}$ na sredini A-ose (Slika 1) [16]. Sredina A-ose je tačka na sredini interkomisuralnog rastojanja.

Granice GC smo, zbog postojanja morfoloških varijacija, standardno definisali (Slika 1) na sledeći način: prednja granica GC (subrostralni segment) je standardizovana tako da postavimo horizontalnu pravu al (paralelno A-osi) duž rostralnog dela sulkusa cinguli i vertikalnu pravu Bl kroz vrh rostruma korporis kalozi (paralelno B-osi), tako da je subrostralni deo GC smešten između ravni alBl i rostral-

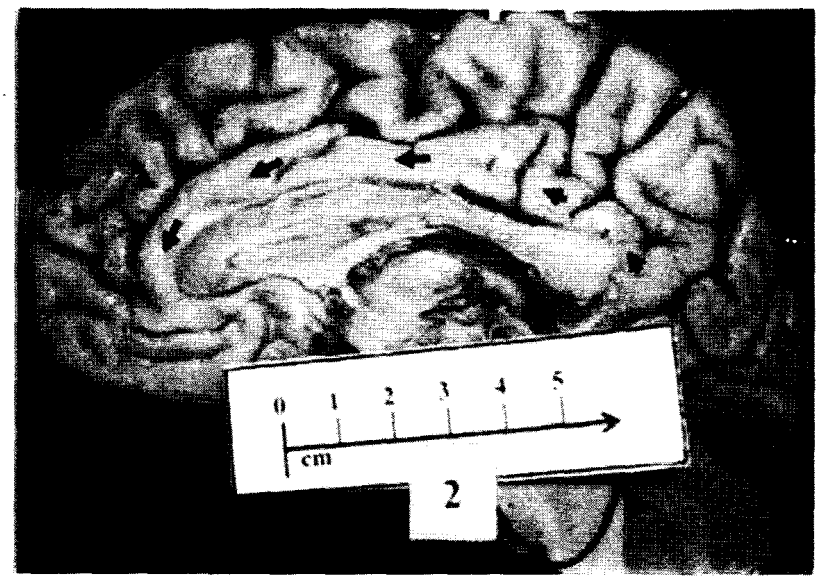

Slika 2. Kontinuirani tip girusa cinguli (bele strelice - žlebovi koji ne presecaju u potpunosti gyrus cinguli)

Fig. 2. The continuous type of the cingulate gyrus (white arrows - sulci which incompletely divide the cingulate gyrus)

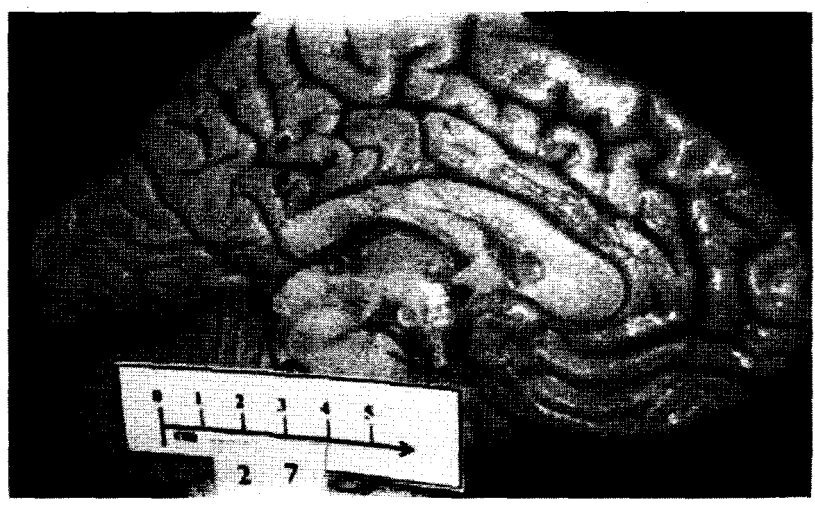

Slika 3. Segmentiran tip girusa cinguli (strelice - sulkus koji u potpunosti preseca gyrus cinguli)

Fig. 3. The segmented type of the cingulate gyrus (arrows sulci which incompletely divide the cingulate gurus)

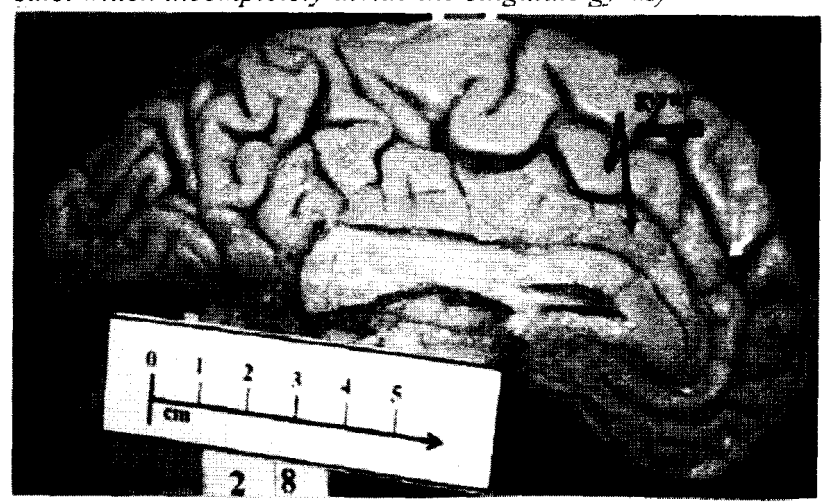

Slika 4. Gyrus cinguli - dvostruki paralelni tip, usled prisustva sulkusa paracinguli (bela strelica - sulcus paracinguli)

Fig. 4. The cingulate gyrus - double parallel type caused by the presence of the paracingulate sulcus (white arrow - paracingulate sulcus)

nih delova sulkusa cinguli i sulkusa korporis kalozi. Zadnji kraj GC (retrosplenijalni segment) nema jas- 
no odredenu granicu prema istmusu giri cinguli pa smo je definisali intersekcijom sulkusa kalkarinusa sa produžetkom pravca sulkusa subparietalisa i pravom a (paralelna sa A osom) koja čini tangentu na splenium corporis callosi. Digitalne fotografije su korišćene kako za morfološku tipizaciju GC tako i za morfometrijska merenja ekstrasulkusne površine GC primenom digitalne AutoCAD planimetrije. AutoCAD 2004 spada u grupu programskih paketa namenjenih crtanju, projektovanju $i$ drugim vidovima primene računara u inženjerskoj praksi, a može se koristiti i za merenje pravilnih i nepravilnih površina. U našoj studiji AutoCAD program smo koristili za merenje površina mekotkivnih struktura mozga [17].

Ispitivanje signifikantnosti razlike morfoloških tipova girusa cinguli vršeno je upotrebom $\chi^{2}$ testa. Signifikantnost razlike u vrednostima površine (desna/leva asimetrija, polni dimorfizam) odredivana je upotrebom Studentovog T-testa.

\section{Rezultati}

U odnosu na izgled i granične žlebove, gyrus cinguli smo podelili na tri osnovna morfološka tipa: kontinuiran tip (GC nije potpuno segmentiran žlebovima); segmentirani tip (GC je podeljen žlebovima na dva ili više segmenata) i dvostruki paralelni tip (double parallel type), gde je zbog postojanja sulcusa paracinguli delimično udvostručen prednji deo GC).

Našli smo sva tri osnovna morfološka tipa GC (kontinuirani tip, Slika 2), segmentirani tip (Slika 3), i dvostruki paralelni tip sa prisutnim sulkusom paracinguli (Slika 4).

Učestalost pojedinih tipova GC prikazana je tabelarno (Tabela 1).

Tabela 1. Učestalost pojedinih tipova gyrusa cinguli (GC) apsolutne vrednosti i procenti

Table 1. The frequency of different types of the cingulate gyrus (GC)-absolute values and percentages

\begin{tabular}{lcccc}
\hline & $\begin{array}{c}\text { Broj hemisfera } \\
\text { Number of } \\
\text { hemisplueres }\end{array}$ & $\begin{array}{c}\text { Kontinuirani tip } \\
\text { Continuous } \\
\text { type }\end{array}$ & $\begin{array}{c}\text { Segmentirani } \\
\text { tip/Segmented } \\
\text { type }\end{array}$ & $\begin{array}{c}\text { Paralelnitip } \\
\text { Parallel lype }\end{array}$ \\
\hline Desno/Right & 42 & $17(40,5 \%)$ & $17(40,5 \%)$ & $8(19 \%)$ \\
Levo/lceft & 42 & $12(28,6 \%)$ & $13(30,9 \%)$ & $17(40,5 \%)$ \\
Muškarci/Male & 52 & $14(26,9 \%)$ & $20(38,5 \%)$ & $18(34,6 \%)$ \\
Žene/licmale & 32 & $15(46,875 \%)$ & $10(31,25 \%)$ & $7(21,875 \%)$ \\
\hline
\end{tabular}

Razlika u učestalosti pojedinih tipova GC kod muškaraca i žena nije statistički značajna: $p>0,05$ $(\mathrm{t}=0,551 ; \mathrm{T}(0,05, \mathrm{~S} . \mathrm{S} .2)=5,99)$. Razlika učestalosti

Tabela 2. Ekstrasulkusna površina girusa cinguli (ukupno 84 hemisfere oba pola) u odnosu na stranu (desno/levo)

Table 2. The extrasulcal surface of the cingulate gyrus in relation to hemisphere (right/left)

\begin{tabular}{|c|c|c|c|c|c|c|}
\hline & $\mathrm{N}$ & $X$ & SD & $\mathrm{CV}$ & Max & Min \\
\hline Desno/Right & 42 & $13,45 \mathrm{~cm}^{2}$ & $2,25 \mathrm{~cm}^{2}$ & $16,7 \%$ & $7,98 \mathrm{~cm}^{2}$ & $8,75 \mathrm{~cm}^{2}$ \\
\hline $\begin{array}{l}\text { Levo/Left } \\
\text { Ukupno }\end{array}$ & 42 & $14,58 \mathrm{~cm}^{2}$ & $2,49 \mathrm{~cm}^{2}$ & $17,1 \%$ & $21,8 \mathrm{~cm}^{2}$ & $9,55 \mathrm{~cm}^{2}$ \\
\hline Total & 84 & $14,02 \mathrm{~cm}^{2}$ & $2,42 \mathrm{~cm}^{2}$ & $17,26 \%$ & $21,8 \mathrm{~cm}^{2}$ & $8.75 \mathrm{~cm}^{2}$ \\
\hline
\end{tabular}

tipova GC na levoj i desnoj strani nije statističli značajna: $p>0,05(t=0,462 ; T(0.05, S . S .2)=5,99)$.

Rezultati merenja ekstrasulkusne površine GC. kao i signifikantnost njene razlike u odnosu na pol $i$ stranu hemisfera prikazani su tabelama (tabele 2 i 3).

Tabela 3. Ekstrasulkusna površina glrusa cinguli u odnosu na pol i stranu (desno/levo)

Table 3. The extrasulcal surface of the cingulate gyrus in relation to sex and hemisphere (right left)

\begin{tabular}{|c|c|c|c|c|}
\hline \multirow[b]{2}{*}{ Hemisfera/Hemisphere } & \multicolumn{2}{|c|}{ Muškarci/1tales } & \multicolumn{2}{|c|}{ Žne/females } \\
\hline & Desna/Righ & $t$ Lova/Left & Desna'Righ & 1 Levalleft \\
\hline$X\left(\mathrm{~cm}^{2}\right)$ & 13,8 & 15.19 & 12.92 & 13.6 \\
\hline $\mathrm{SD}\left(\mathrm{cm}^{2}\right)$ & 2.22 & 2.15 & 2,49 & 2.76 \\
\hline$C V(\%)$ & 16.1 & 14.1 & 19.3 & 20,3 \\
\hline $\operatorname{Max}\left(\mathrm{cm}^{2}\right)$ & 17,33 & 19.68 & 17.98 & 21.8 \\
\hline $\operatorname{Min}\left(\mathrm{cm}^{2}\right)$ & 10.55 & 11.7 & 8.75 & 9.55 \\
\hline
\end{tabular}

Rezultati (na 84 hemisfere) pokazuju statistički značajno veću ekstrasulkusu povišinu GC na levim hemisferama $(p<0,05)$ za $1,13 \mathrm{~cm}^{2}$.

Istraživanjem polnih razlika utvrdili smo veću površinu GC levih hemisfera kod oba pola, ali je ova desno-levo razlika statistički značajna samo kod muškaraca $(p<0,05)$. Razlika u ekstrasulkusnoj površini GC između desnih muških i desnih ženskih hemisfera nije bila statistički značajna $(p>0,05)$, dok je između levih muških i levih ženskih hemisfera utvrđeno da je statistički značajno veća uva površina kod osoba muškog pola $(p<0,05)$.

\section{Diskusija}

Poznavanje tačnih granica i varijabilnosti vijuga i žlebova važno je u utvrđivanju citoarhitektonskih oblasti [18], a poznavanje morfološkil tipova vijuga ili žlebova može da posluži i u genetskim istraživanjima mozga (načina njilovog eventualnog nasleđivanja) [19]. Encefalometrijske studije su značajne za upoznavanje opsega varijacija, polnog dimorfizma i eventualnog morfološkog supstrata lateralizacije moždanih funkcija. Zapremina GC je smanjena kod bipolarnih poremećaja raspoloženja [10]. Kod postraumatskih stresnih poremećaja smanjena je površina desnog prednjeg cingularnog korteksa (area 24) [20], dok je njeno relativno smanjenje udruženo sa psihičkim poremećajima u autizmu [21]. O kompleksnosti i značaju funkcije GC svedoči i činjenica da se hipoperfuzija krvi kroz zadnji cingularni korteks može uočiti $i$ do dve godine pre pojave simptoma koji zadovoljavaju kliničke kriterijume za dijagnostikovanje Alchajmerove bolesti [22]. Razvoj neuroimidžinga povećava interesovanje za morfologiju mozga, što se odnosi i na dijagnostiku i terapiju velikih depresivnih poremecaja [23]. Neuroimidžing studije prednjeg cingularnog korteksa nisu dale jasnu sliku abnormalnosti kod shizofrenije, pa je potrebna preciznija anatomija ove regije [24]. Takođe, istraživanja ukazuju na ulogu holecistokinina (CCK) u patogenezi shizofrenije, 
kao i način kortikalne obrade impulsa uz učešće kortikalnih interneurona [25].

Iako su brojnija istraživanja morfologije žlebova nego vijuga medijalne strane hemisfere coveka $[6$, $15,26,27]$, u analizi te literature pomaže činjenica da podaci o postojanju sulkusa paracinguli u stvari ukazuju na prisustvo dvostrukog paralelnog tipa GC. Nalaz paracingulatnog žleba na 40 mozgova češće levo (28 slučajeva) nego desno (13 slučajeva) odgovara našim nalazima [27]. Vogt i saradnici [6] uočili su na 20 mozgova paracingulatni žleb u $35 \%$ slučajeva i u tim slučajevima "dvostrukog sulkusa cinguli" pravi sulcus cinguli je bio plići. Mi smo, proučavajući učestalost pojedinih morfološki tipova GC, utvrdili da se skoro podjednako često javlja segmentirani $(35,7 \%)$ i kontinuirani tip $(34,5 \%$ slučajeva), a dvostruki paralelni tip nešto ređe $(29,8 \%)$. U detaljnoj studiji na 247 osoba izražen paracingulatni žleb nađen je češće levo $(54 \%)$ nego desno $(37 \%)$, a odsutan je bio u $8 \%$ slučajeva levo $\mathrm{i}$ u $15 \%$ desno [26]. U ovom istraživanju više parametara moždanih žlebova jedina signifikantna razlika postoji samo u slučaju paracingulatnog žleba koji je kod muškaraca prisutan ali slabo izražen, dok je kod žena ili odsutan ili jako razvijen [26]. Nismo uočili statistički značajne razlike u učestalosti morfoloških tipova GC kako prema strani hemisfera (desna-leva) tako i prema polu osobe, iako smo kod žena kontinuirani tip našli u $46,8 \%$, a kod muškaraca samo u $26,9 \%$ slučajeva.

$\mathrm{Mi}$ smo našli statistički značajno veću $(\mathrm{p}=0,0315)$ ekstrasulkusnu površinu GC na levim hemisferama $\left(\mathrm{za} 1,13 \mathrm{~cm}^{2}\right)$ od površine na desnim (desno $13,45 \mathrm{~cm}^{2}$, levo $14,58 \mathrm{~cm}^{2}$ ), kao i postojanje statistički značajne pozitivne korelacije između površine desnog i levog $G C(r=0,7603)$. Naši rezultati ukazuju na desno-leve razlike GC i fenomen lateralizacije funkcija sa dominantom levom hemisferom i u limbičkim kortikalnim strukturama kakav je GC. Ekstrasulkusna površina levog prekuneusa, vijuge medijalne strane hemisfere u neposrednom odnosu sa zadnjim delom GC veća je od one kod desnog ali bez statistički signifikantne razlike. Takođe, nije bilo statistički signifikantne levo-desne razlike u površini prekuneusa ni u muškaraca niti kod žena. Prekuneus levih hemisfera muškaraca ima statistički visokosignifikantno veću površinu u odnosu na prekuneus levih hemisfera žena [28].

Rasdolsky [29] je prvi skrenuo pažnju na morfološke asimetrije hemisfera $i$ istovremeno na levodesne razlike u autonomnim funkcijama i inervaciji.
Naši morfometrijski nalazi su u skladu sa koncepcijom komplementarne specijalizacije hemisfera, gde je $91 \%$ populacije desnoruko sa dominantnom levom hemisferom, $6 \%$ levoruko sa dominantnom levom hemisferom, a $3 \%$ je levoruko sa dominantom desnom hemisferom [30]. Međutim, korelacija veće površine prednjeg desnog GC sa intenzitetom simptoma aleksitimije [31], dispozicijom strahu i anticipacijom brige [32] ukazuju na lateralizaciju i dominaciju desne hemisfere u procesiranju emocija.

$U$ istraživanju polnih razlika našli smo statistički značajno veću $(p=0,0459)$ esktrasulkusnu površinu levog GC kod muškaraca nego kod žena (muškarci levo: $15,9 \mathrm{~cm}^{2}$ žene - levo: $13,6 \mathrm{~cm}^{2}$ ). Ova površina desnog GC je veća kod muškaraca (za $0,88 \mathrm{~cm}^{2}$ ) nego kod žena $(p>0,05)$, ali razlika nije statistički značajna. I kod muškaraca i kod žena postoji statistički značajna pozitivna korelaciju između površina desnog i levog GC (muškarci: $r=0,6831$ ), ali je posebno izražena kod žena $(r=0,8483)$, što smo ranije našli i za ekstrasulkusnu površinu levog i desnog prekuneusa [32]. Naša istraživanja su potvrdila postojanje polnih razlika u ekstrasulkusnoj površini $\mathrm{GC}$, kao što je to slučaj i sa ranijim studijama [15, 26], dok morfološki tipovi GC ne pokazuju takve razlike na ispitivanom uzorku.

\section{Zaključak}

U studiji morfoloških tipova girusa cinguli čoveka utvrdili smo skoro podjednako učestalo prisustvo njegovog segmentiranog $(35,7 \%)$ i kontinuiranog tipa $(34,5 \%)$, a nešto manje dvostrukog paralelnog tipa $(29,8 \%)$. U učestalosti morfološki tipova girusa cinguli prema strani hemisfera (desno-levo) ili prema polu nema statistički značajne razlike ( $p>0,05)$. Medutim, digitalna AutoCAD morfometrija girusa cinguli čoveka pokazala je postojanje polnih i desno-levih razlika. Ekstrasulkusna površina levog girusa cinguli statistički je značajno veća $(p<0,05)$ za $1,13 \mathrm{~cm}^{2}$ od površine desnog (desno: $13,45 \mathrm{~cm}^{2}$; levo: $\left.14,58 \mathrm{~cm}^{2}\right)$. Ustanovljena je signifikantno veća površina levog girusa cinguli kod muškaraca (muškarci - levo: 15,9 cm²; žene - levo: $13,6 \mathrm{~cm}^{2}$; $\mathrm{p}<0,05)$.

lako je studija ukazala na dominantost leve hemisfere i za limbičku koru čoveka, na osnovu komparativne analize utvrđen je značaj ispitivanja relativnih volumetrijskih parametara u izučavanju fenomena lateralizacije psihičkih funkcija.

\section{Literatura}

1. Krmpotić-Nemanjić J. Anatomija čovjeka. Zagreb: Jugoslovenska Medicinska Naklada; 1979. 1983.

2. Creutzfeldt OD. Cortex cerebri. Berlin: Springer-Verlag;

3. Guyton AC. Medicinska fiziologija. 1. izd. Beograd: Medicinska knjiga; Savremena Administracija; 1996.

4. Powell EW, Hines G. The limbic sistem: an interface. Behav Biol 1974;(12):149-64.
5. Brodmann K. Vergleichende lokalizationslehre der grosshirnrinde. 2. Aufl. Leipzig: Verlag JA Barth; 1925.

6. Vogt AB, Nimchinsky AE, Vogt JL, Hof RP. Human cingulate cortex: Surface Features, flat maps, and cytoarchitecture. J Comp Neurol 1995:359:490-506.

7. Wenderoth N, Debaere F. Sunaert S. Swinnen SP. The role of anterior cingulate cortex and precuneus in the coordination of motor behaviour. Eur J Neurosci. 2005:22( 1):235-46. 
8. Diehl B, Dinner DS, Mohamed A, Najm I, Klem G. LaPresto $\mathrm{E}$, et al. Evidence of cingulate motor representation in humans. Neurology 2000;55(5):725-8.

9. Mitelman SA, Shihabuddin L, Brickman AM. Hazlett EA, Buchsbaum MS. Volume of the cingulate and outcome in schizophrenia. Schizophr Res 2005:72(2-3):91-108.

10. Bouras C, Kovari E, Hof PR. Riederer BM, Giannakopoulos $P$. Anterior cingulate cortex pathology in schizophrenia and bipolar disorder. Acta Neuropathol (Berl) 2001;102(4): 373-9.

11. Haznedar MM, Buchsbaum MS, Hazlett EA, Shihabuddin L, New A, Siever LJ. Cingulate gyrus volume and metabolism in the schizophrenia spectrum. Schizophr Res 2004;71 $(2-3): 249-62$

12. Bromm B. The involvement of the posterior cingulate gyrus in phasic pain processing of humans. Neurosci Lett. 2004; 361(1-3):245-9.

13. Perović D. Anatomija čovjeka. Knjiga II. Beograd - Zagreb: Medicinska knjiga; 1964.

14. Testut L. Anatomia umana: neurologia. Torino: Unione tipographico editrice Torinese; 1917.

15. Stanczyk JL. Variation of the gyrus cinguli and sulcus cinguli in phylo and ontogenesis. Folia Morphol (Warsz). 1983;42(4):243-69.

16. Talairach J, David M, Tournoux P, Corredor H, Kvasina T. Atlas d'anatomie stereotaxique des noyes gris centreux. Paris: Masson; 1957.

17. Spasojević G ,Stojanović Z, Šuščević D, Malobabić S, Sexual dimorphism of the human corpus callosum: digital morphometric study. Vojnosanit Pregl 2006:63(11):933-8.

18. Morris R, Paxinos G, Petrides M. Architectonic analyisis of the human retrosplenial cortex. J Comp Neurol 2000; 421:14-28

19. Baare WFC, Hilleke E, Hulshoff P, Boomsma DI, Posthuma D, de Geus EJC, et al. Quantitative genetic modeling of variation in human brain morphology. Cerebral Cortex 2001; 11(9):816-24.

20. Kitayama N, Quinn S, Bremner JD. Smaller volume of anterior cingulate cortex in abuse-related posttraumatic stress disorder. J Affect Disord 2006;90(2-3):171-4.

21. Haznedar MM, Buchsbaum MS, Metzger M, Solimando A, Spiegel-Cohen J, Hollander E. Anterior cingulate gyrus volume and glucose metabolism in autistic disorder. Am J Psychiatry. $1997 ; 154(8): 1047-50$.

22. Huang $C$, et al. Cingulate cortex hypoperfusion predicts Alzheimer's disease in mild cognitive impairment. BMC Ncurol. 2002:2:9

23. Hamani C. Mayberg H. Snyder B, Giacobbe P, Kennedy $\mathrm{S}$, Lozano A. Deep brain stimulation of the subcallosal cingulate gyrus for depression: anatomical location of active contacts in clinical responders and suggested guideline for targeting. J Neurosurg 2009; 11 1:1209-15.

24. Mc Cormick LM, Ziebell S, Nopoulos P, Cassell M, Andreasen NC, Brumm M. Anterior cingulate cortex: an MRIbased parcellation method. NeuroImage 2006;32:1167-75.

25. Puškaš L. Draganić-Gajić S, Malobabić S, Puškaš N, Krivokuća D. Stanković G. Morfological and laminar distribution of cholecistokinine - imunoreaktive neurons in cortex of human inferior parietal lobule and their clinical significance. Med Pregl 2008;LXI(9-10):452-7.

26. Paus T, Tomaiuolo F. Otaky N. MacDonald D, Petrides $\mathrm{M}$, Atlas J, et al. Human cingulate and paracingulate sulci: pattern, variability, asymmetry and probabilistic map. Cerebral Cortex 1996;6:207-14.

27. Ide A, Dolezal C, Fernandez M, Labbe E, Mandujano $R$. Montes $S$, et al. Hemispheric differences in variability of fissural patterns in parasylvian and cingulate regions of human brains. J Comp Neurol 1999;410:235-42.

28. Spasojević G. Malobabić S. Suščević D, Miljković Z̆. Morfometrijska varijabilnost prekuneusa u odnosu na pol i hemisferu mozga čoveka. Vojnosanit Pregl 2004;61(4):365-70.

29. Rasdolsky $T$. The asymmetry of the hemispheres of the brain in mand and animals. J Nerv Ment Dis. 1927;62:119-32.

30. Ganong WF. Pregled medicinske fiziologije. Beograd: Savremena administracija; 1993.

31. Gundel H, et al. Alexithymia correlates with the size of the right anterior cingulate. Psychosom Med 2004;66(1):13240 .

32. Pujol L, Lopez A, Deus J, Cardoner N, Vallejo J, Capdevila A, et al. Anatomical variability of the anterior cingulate gyrus and basic dimensions of human personality. Neuroimage. 2002;15(4):847-55. 


\section{Summary}

\section{Introduction}

The frequency of different morphological types and extrasulcal (visible) surface area of the cingulate gyrus, were measured and analysed in order to obtain more precise data about morphology, right/left and sex differences in the human brain.

\section{Material and methods}

The study included 42 brains (84 hemispheres) from persons of both sexes and of different age (26 males, 16 females, 20-65 years old), without neuropathological changes. After fixation in $10 \%$ formaline (3-4 weeks) and removal of meninges the brains were photographed under standard conditions by digital camera. Following determination of morphological type, regions of interest of cingulate gyrus were determined in stereotactic system system of coordinates and the extrasulcal surface was measured by digital AutoCAD planimetry.

Results and discussion

Three basic morphological types of cingulate gyrus were found: the continuous type (34.5\%), segmented type (35.7\%) and double paralel type $29.8 \%$. There was no statistically significant difference in the frequency of morphological types related to the side (right/lefi) or sex (p:0.05). The area of extrasulcal cortex of cingulate gyrus was statistically significantly (p) (0.05) larger on the left hemispheres (for 1.13 ('m) than on the right aleft: $14.58 \mathrm{~cm}$; right: $13.45 \mathrm{~cm}$. The extrasulcal surfice of the left cingulate gyrus was significantly larger $(p-0.05)$ in males (males $15.9 \mathrm{~cm}$ : females - $13.6 \mathrm{~cm}$ ), while for the right cingulate gyrus this difference was not significtint.

\section{Conclusion}

Morphometry indicated sex and rightilefi differences of extrasulcal surface area of the human cingulate glvus. However, the morphological analysis itself did not indicate corresponding differences, suggesting complexity of the problem of sex dimorphism and of right/left asymmetries in the domain of limbic cortex.

Key words: Gyrus Cinguli + anatomy and histology; Humans; Sex Characteristics; Morphogenesis; Body Patterning

Prihvaćen za štampu 10. XII 2007.

BIBLID.0025-8105:(2009):LXII:1-2:51-56 